\title{
Generational Shifts in Managerial Values and the Coming of a Unified Business Culture: A Cross-National Analysis Using European Social Survey Data
}

\author{
André van Hoorn ${ }^{1}$ (D)
}

Received: 10 March 2016/Accepted: 24 February 2017/Published online: 14 March 2017

(c) The Author(s) 2017. This article is published with open access at Springerlink.com

\begin{abstract}
In a globalizing world, cross-national differences in values and business culture and understanding these differences become increasingly central to a range of organizational issues and ethical questions. However, various concerns have been raised about extant empirical research on cross-national dissimilarities in the cultural values of managers (what we refer to as managerial values) and the development of a unified business culture. This paper seeks to address three such concerns with the literature on convergence versus divergence of cultural values. It develops an empirical approach to the study of changing business cultures that revolves around birth cohorts and intergenerational values shifts and aims to advance empirical knowledge of the dynamics of cross-national differences in the cultural values of managers. We use time-series data covering 68,708 managers and are able to consider a sample of 32 countries that represent more than half of the cultural clusters recognized in the literature. Results reveal diverse shifts in managerial values across birth cohorts with cross-national dissimilarities waning for some basic cultural dimensions ("convergence"), remaining stable for other dimensions ("cultural stability"), and becoming more pronounced for other dimensions still ("divarication"). Moving beyond the standard convergence/divergence taxonomy, we conclude that a fullfledged convergence-stability-divarication perspective provides the best basis for thinking about the subtle ways in which business cultures are changing.
\end{abstract}

André van Hoorn

A.van.Hoorn@fm.ru.nl

1 Institute for Management Research, Radboud University, PO Box 9108, 6500 HK Nijmegen, The Netherlands
Keywords Values · Birth cohorts · Culture · Convergence $\cdot$ Stability - Divarication - Divergence . Period effects

\section{Introduction}

In a globalizing world, cross-national differences in values and business culture and understanding these differences become increasingly central to a range of organizational issues and ethical questions. Values affect how people behave across different situations (Meglino and Ravlin 1998; Schwartz 1992) and have been linked to a variety of ethical issues such as judgment of moral behavior in the workplace (Finegan 1994), fair trade consumption (Doran 2009), the evaluation of questionable consumer practices (Steenhaut and Van Kenhove 2006), and ethical decision making more broadly (Fritzsche 1995; Fritzsche and Oz 2007). With regard to globalization, the traditional concern is whether typical American management philosophies and leadership styles would also work abroad. Accordingly, starting with Harbison and Myers (1959) and Inkeles (1960), among others, much effort has gone into investigating cross-national differences in the cultural values of managers (what we refer to as managerial values) and determining whether countries' business cultures (i.e., the cultural values of business managers) are converging over time to become more similar or not (Dunphy 1987; Leung et al. 2005; Ricks et al. 1990; Weber 2015a, b). Still, however, scholarly analysis of the dynamics of cross-national differences in the cultural values of managers and cross-nationally converging or diverging business cultures does not seem to have kept up with the extent to which globalization has permeated business life. Particularly, there is a growing concern with the limitations of existing empirical contributions to the 
convergence versus divergence debate, raising the question how much we truly know about the dynamics of cross-national values differences and changing business cultures. Extant empirical work, summarized in the top rows of Table 1, faces three key problem areas.

The first problem area is the use of static country comparisons. A unified business culture may evolve as result of cross-national changes in managerial values. Studying convergence/divergence therefore means studying the evolution of cultural values. Only by employing time-series data can researchers distinguish between genuine cultural convergence/divergence and confounding factors, specifically age (or life stage) effects and period effects (Hofstede 2001; Lyons and Kuron 2014; Twenge et al. 2010). Notwithstanding, cross-sectional comparisons of mean values scores of countries are the norm in this literature, and time-series research is scarce (Ralston 2008) (column 1 in Table 1).

The second problem area is that the quantitative convergence versus divergence literature has not paid much attention to birth cohorts and generational shifts in the cultural values of managers as key carriers of changing business cultures (Inglehart and Welzel 2005; Mannheim 1928/1929; Ryder 1965). Values differences between birth cohorts have, in fact, been shown to be important (Joshi et al. 2010, 2011; Lyons and Kuron 2014; Twenge et al. 2010). However, not many studies explicitly recognize the importance of birth cohorts, which are also sometimes called generations and can be straightforwardly defined as a group of people born in the same period, when studying converging or diverging business cultures (column 2 in Table 1). Studying birth cohorts, in turn, requires that we are able to distinguish properly between cohort effects and confounding age and period effects (Hofstede 2001; Lyons and Kuron 2014; Twenge et al. 2010), further highlighting the need for time-series data that involve more than one birth cohort, each of which is measured at multiple points in time.

Finally, the third problem area is the limited international generalizability of extant evidence on cultural convergence/divergence. The convergence versus divergence literature has considered only a handful of countries (Ralston 2008), and we need a much larger number if we want to make credible international generalizations, typically minimum seven countries although a sample of at least 10 countries is preferred (Franke and Richey 2010). Studies usually consider only the US vis-à-vis China or Japan, leaving a large gap in our knowledge concerning, among others, such BRIC countries as Russia or Central and Eastern European (CEE) countries more generally (Ralston 2008). The number of countries considered is quite often two, and no study comes close to Franke and Richey's (2010) minimum of seven, let alone 10 countries (column 3 in Table 1).

Conclusion from these three vital problem areas is that the quantitative literature on cross-national differences in the cultural values of managers and the dynamics of business cultures faces some important challenges. Existing empirical work seems incomplete as well as suffering some important methodological problems. In short, there is an urgent need to try putting the convergence versus divergence debate and our understanding of cultural (dis)similarities in managerial values on more solid evidentiary footing.

Table 1 Research designs in studies of cultural convergence/divergence and the dynamics of (managerial) values

\begin{tabular}{|c|c|c|c|c|}
\hline Study & $\begin{array}{l}1 \\
\text { Type of data }\end{array}$ & $\begin{array}{l}2 \\
\text { Samples compared }\end{array}$ & $\begin{array}{l}3 \\
\text { Countries studied }\end{array}$ & $\begin{array}{l}4 \\
\text { No. of } \\
\text { individual } \\
\text { observations }\end{array}$ \\
\hline Vertinsky et al. (1990) & Cross-sectional & Countries & Canada, China, and Hong Kong & 155 \\
\hline Ralston et al. (1997) & Cross-sectional & Countries & China, Japan, Russia, and USA & 855 \\
\hline Heuer et al. (1999) & Time-series, two sample points & Countries & Indonesia and USA & 150 \\
\hline Egri and Ralston (2004) & Cross-sectional & Birth cohorts across countries & China and USA & 1558 \\
\hline Ralston et al. (2006) & Time-series, two sample points & Countries & China, Hong Kong, and USA & 776 \\
\hline Twenge et al. (2010) & Time-series, three sample points & Birth cohorts, within country & USA & 16,507 \\
\hline Present study & Time-series, up to six sample points & Birth cohorts across countries & $\begin{array}{l}32 \text { countries, including CEE } \\
\text { countries, Russia, Ukraine, et } \\
\text { cetera }\end{array}$ & 68,708 \\
\hline
\end{tabular}

With the exception of Twenge et al.'s (2010) study of time-series data on different birth cohorts, this overview refers as much as possible to studies of the values of managers as the group of people of most interest to organization and business ethics scholars. Practically, this means that we exclude studies such as those by Beugelsdijk et al. (2015) on the attitudes and opinions of the general public and by Pekerti and Arli (2015) on migrants in Australia, even though these studies fit the presented overview on the count of considering birth cohorts. The complete set of countries in the present study is Austria, Belgium, Bulgaria, Switzerland, Cyprus, Czech Republic, Germany, Denmark, Estonia, Spain, Finland, France, Greece, Croatia, Hungary, Iceland, Ireland, Israel, Italy, Lithuania, Luxemburg, Netherlands, Norway, Poland, Portugal, Russia, Sweden, Slovenia, Slovakia, Turkey, UK, and Ukraine (see Table 2) 
This paper seeks to address the above challenges, focusing on the presenting of descriptive evidence on generational shifts in the cultural values of managers and the development of a unified business culture across a large set of countries. Doing so requires us to develop an empirical approach with three outstanding features. First, we take birth cohorts across countries as the main unit of analysis, this way providing the analysis with a thorough grounding in theories of the role of cohorts and cohort replacement in cultural value change (Inglehart and Welzel 2005; Mannheim 1928/1929; Ryder 1965). Second, we consider time-series data with cultural values measured at up to six points in time. Third, we foster international generalizability by examining the dynamics of business cultures for a large sample of countries that comprises more than half of the world's main cultural clusters. The paper thus integrates a theory-driven focus on birth cohorts with the power of time-series data. Practically, we analyze a baseline sample of 68,708 managers as the group of people of most interest to organization and business ethics scholars and consider intergenerational values differences across 32 European but culturally highly diverse countries measured biannually from 2002 to 2012 (bottom row of Table 1).

Our study makes several contributions. Methodologically, we present a design for the study of cultural convergence that takes theories of cohorts and value change as its starting point and provide what we hope will be a valuable blueprint for future research on the dynamics of managerial values and countries' business cultures. Substantively, the paper helps advance our empirical knowledge of cross-national (dis)similarities in the cultural values of managers and the dynamics therein. Specifically, our analysis brings forth large-scale cross-country evidence on shifts in the cultural values of managers as well as systematic insight on the extent to which business cultures are unifying or not. Results reveal highly diverse shifts in the cultural values of managers across birth cohorts. There is evidence of convergence, meaning a decrease in cross-national values dissimilarities, but also evidence of stable cultural differences and even some evidence of increasing cross-national value dissimilarities, what we call divarication. The convergence versus divergence debate has not yet paid much attention to the possibility of divarication, meaning that cross-national differences in cultural values are not only stable-what has come to be called divergence (Webber 1969)—but are, in fact, increasing. Given our findings, as well as the generic attractiveness of having a complete taxonomy, however, we propose that a full-fledged convergence-stability-divarication perspective provides the best basis for thinking about the subtle ways in which business cultures are changing.

The above contributions notwithstanding, we readily acknowledge the limitations of the study presented here. The chief goals of this paper are simply to develop a cohort-based empirical approach to studying cultural convergence and to present large-scale evidence on the development of a unified business culture. As such, it is beyond the scope of the present paper to develop novel theoretical insights on the specific psychological processes that may bring about systematic shifts in the cultural values of managers from one birth cohort to the next. We find that there have been several interesting contributions to this specific issue in recent years, specifically concerning the culture dimension involving the relationship between individuals and groups (e.g., Hamamura 2012). This paper, then, might provide empirical insights that help inspire more of such studies. Meanwhile, we appreciate how specific features of our analysis and empirical approach are bound to raise some questions themselves. Questions or concerns that did not readily emerge in the context of static, bi-country comparisons of managerial values can suddenly gain salience in an analysis that involves a large number of countries and uses birth cohorts across countries as the main unit of analysis. We thus conclude by laying out several important directions in which future research can expand on the present study.

\section{Values and Dimensions of Cultural Value Orientations}

The importance of values for social science and people and societies in general has long been recognized (Hofstede 2001; Meglino and Ravlin 1998; Rohan 2000; Schwartz and Bilsky 1987). Values are thus widely researched, mostly in psychology, but also in organization research (see, for instance, England 1967 and Kelly and Reeser 1973 for early work). Values are evaluative and direct individuals to select between alternative courses of action. A definition is that values are concepts about desirable end states or behavior that are not tied to specific situations (Schwartz and Bilsky 1987, p. 551). Hence, values are a chief driver of individuals' actions and the choices that they make, including those concerning various ethical issues (Fritzsche 1995; Fritzsche and Oz 2007; Van Hoorn 2015b).

A key feature of values is their stability (Inglehart and Welzel 2005; Meglino and Ravlin 1998; Rohan 2000). People acquire their values early in life, during their preadult formative years. The main influences are personal experiences and, especially, socialization processes. The latter involve one's parents, siblings, family, peers, teachers, the media, etc. as agents instilling a particular value system in the individual (Hitlin and Piliavin 2004; Hofstede 2001; Inglehart and Welzel 2005; Meglino and Ravlin 1998). For individuals from a given birth cohort, we may add to this the experience of a certain societal environment, 
such as critical life-history events (e.g., a war) and socioeconomic circumstances that they share with others in their cohort (e.g., the Great Depression). A concrete example is the effect of the $9 / 11$ terrorist attack on the USA on the values of teenagers (Murphy et al. 2006). Once acquired during their pre-adult formative years, individuals' values remain relatively stable over their life course. Overall, birth cohorts are thus expected to have somewhat similar values and to exhibit notable values dissimilarities with other birth cohorts. This is not to deny, however, that values can exhibit so-called age (or life stage) effects (Joshi et al. 2011; Lyons and Kuron 2014; Twenge et al. 2010). The basic idea behind these value influences is that people's values continue to evolve also during adulthood because the specific decisions that individuals make in their personal and professional lives further define their adult identities. A striking illustration is the finding of Desai et al. (2014) that single men develop more negative attitudes toward working women after getting married to a woman that is not employed herself.

From a diverse literature (cross-cultural), psychologists and other social scientists have slowly developed two standard value frameworks that are widely accepted, one concerning personal values (individual-level constructs) and one concerning cultural values (societal-level constructs) (Schwartz 1992, 1994). Both frameworks are mostly the work of Shalom Schwartz, where the framework for universal personal values was developed first and in extensive cooperation with Wolfgang Bilsky (Schwartz 1992; Schwartz and Bilsky 1987, 1990). Given our interest in countries' business culture, the cultural values framework (Schwartz 1994, 1999, 2006) is the relevant framework, however. ${ }^{1}$ Similar to the first framework, this framework was

\footnotetext{
${ }^{1}$ Of course, other frameworks of either personal (e.g., Rokeach 1973; England) or cultural values (e.g., Hofstede 2001; GLOBE) exist. We opted for using Schwartz's framework as it builds on Rokeach's pioneering work and has become the main values framework in psychology. We should note, though, that both Rokeach's framework and Schwartz's framework have been proven to be insightful for business ethics research (see, for example, Graf et al. 2011, 2012 and Weber 2015a, b). Similarly, we should note that, though often hailed as the superior framework (e.g., Brett and Okumura 1998), Schwartz's framework has also been criticized, not least for lacking empirical applications testifying to the framework's validity (Steenkamp 2001). Much progress has been made on this point, however, including in business ethics, research, where Schwartz's values have been linked to a variety of moral behaviors and (un)ethical practices (e.g., Doran 2009; Fritzsche and Oz 2007; Van Hoorn 2015a). Finally, there is also an important practical advantage to using Schwartz's framework, which is that his measures are widely used in publicly available data sources, including the European Social Survey (ESS) as used by us. In contrast, other popular and insightful frameworks of cultural differences with publicly available data, particularly those by GLOBE or Hofstede, provide country scores but do not have detailed individual-level data available that would allow considering a specific group like managers.
}

developed from ex ante theorizing on the specific dimensions needed to capture societal differences in value orientations. This ex ante theorizing not only suggested the basic cultural value orientations, seven in total (Fig. 2 in Appendix), but also systematic interrelations between these basic orientations. The remainder of this section provides a more detailed discussion of Schwartz's culture framework and the different dimensions of cultural values in this framework. Readers that are already familiar with this framework may therefore wish to skip ahead to the next section, which relates the concept of birth cohorts to cultural change and presents our hypotheses.

Starting point for Schwartz's theory is the idea that cultural values or cultural value orientations-we use the terms interchangeably-evolve in response to critical issues that all societies face and for which each society needs to develop an appropriate response (Schwartz 2006, p. 140). There are three such issues: the guaranteeing that individuals behave responsibly, in ways that sustain society's social fabric; the regulation of individuals' relations to both the natural and the social world; and the relation between the individual and the group and the boundaries between them. The response to each of these three issues can be described in terms of two polar alternatives: (1) Egalitarianism versus Hierarchy; (2) Harmony versus Mastery; and (3) Embeddedness versus Autonomy, where Autonomy is understood to consist of two further components, namely Intellectual Autonomy and Affective Autonomy. With Autonomy subdivided into two, this theorizing thus rendered seven basic cultural value orientations. The description of these seven dimensions of cultural values is as follows (taken from Schwartz 2006, pp. 140-141): Egalitarianism is about recognizing others as moral equals and emphasizes the basic interests shared by all humans; Hierarchy is about the unequal distribution of power and resources and the taking for granted of this distribution; Harmony is about fitting into the world as it is, not trying to change or exploit it but to understand it; Mastery is about the encouragement of active self-assertion and changing the natural and social environment to attain group or personal goals; Embeddedness is about being a member of a collective, sharing goals within a collective, in-group solidarity and respecting traditional orders; Intellectual Autonomy is about encouragement for individuals to pursue their own ideas and intellectual directions; and, finally, $A f$ fective Autonomy is about encouragement for individuals to pursue positive affective experiences for themselves.

In addition to the three times two polar extremes (Egalitarianism vs. Hierarchy; Harmony vs. Mastery; and Embeddedness vs. [Intellectual and Affective] Autonomy), the cultural value orientations in the Schwartz framework are further structured by their mutual compatibility. Certain sets of cultural value orientations can share an underlying idea or premise, facilitating the simultaneous implementation and pursuit of these values in society (Schwartz 
2006, p. 141). Clearly, the polar responses are mutually incompatible; one cannot achieve harmony while also striving for mastery, for instance. Other dimensions are more compatible, however, as they refer to objectives that can be achieved without one inevitably coming at the expense of the other. Egalitarianism and Harmony, for instance, refer to related matters like equality, justice, unity, and peace. Incorporating this logic of (in)compatibility, the seven cultural value dimensions can be placed in a circumflex structure, where the position of the dimensions on the circle relative to each other reflects the dimensions' structural interrelatedness (Fig. 2 in Appendix). Adjacent cultural value orientations are compatible, whereas cultural value orientations that are located opposite to each other are incompatible.

\section{Birth Cohorts and Changing Business Cultures}

\section{Value Change and Cultural Convergence/ Divergence}

Given the importance of values for organizations (Meglino and Ravlin 1998) and individual behavior (Rohan 2000; Schwartz 1992), the dynamics of values are of crucial interest, both to practitioners and to business and organization scholars. Do values differ across birth cohorts and are values converging to become more similar across countries or not? The interest in intergenerational differences is more recent, while the idea of convergence of cultural values has a long history in business and organization research. Focusing on cultural convergence, many authors have summarized the arguments in this literature to reflect two positions, referred to as convergence or divergence, respectively. ${ }^{2}$ These two perspectives are easy to comprehend in terms of their predictions concerning the

\footnotetext{
${ }^{2}$ See Joshi et al. (2011) for a summary of the literature on birth cohorts and value differences between birth cohorts in business and organization research. The forces that give rise to differences in values between birth cohorts are largely the same forces that underlie changing cultural dissimilarities between countries. Meanwhile, the idea of crossvergence as developed by Ralston and colleagues (e.g., Ralston et al. 1997) can be seen as a third perspective on changing (managerial) values, in addition to classic convergence and divergence. However, the concept of crossvergence has been heavily criticized, notably for making a distinction between national economic ideology and national culture where most cross-cultural researchers would agree that these are essentially similar phenomena that are both directly associated with the values of the members of a society (Witt 2008; see also, e.g., Pekerti and Arli 2015). More generally, the definition of crossvergence is so loose that it applies to any hybrid case in which convergence does not occur for each distinct cultural value dimension considered (Maseland and Van Hoorn 2017). Given these rather fundamental limitations, in the remainder of this paper we do not consider the crossvergence perspective.
}

dynamics of cultural values and, particularly, of cross-national differences therein. For now, we disregard the mechanism behind changing managerial values (but see below). The convergence perspective can then simply be understood as cultural values becoming more similar over time with existing differences somehow giving way to a more universal managerial value system (Webber 1969). Studies favoring this idea are many, including such seminal works as Harbison and Myers (1959) and Inkeles (1960).

The divergence perspective, in contrast, finds that crossnational variation is substantial and that differences in business culture and managerial values between countries persist. Geert Hofstede is a most famous proponent of the divergence view. He finds, for instance, that "national value systems should be considered given facts, as hard as a country's geographical position or its weather" (Hofstede et al. 2010, p. 20) and that "for the next few hundred years at least, and probably for millennia afterward, countries will remain culturally diverse" (Hofstede et al. 2010, p. 473) (see, also, for instance, Hofstede 2001, p. 34, p. 36, p. 73). Importantly, as alluded to in the introduction, the term divergence is here thus not used in the sense of "growing apart," which can be confusing since it is at odds with the dictionary definition of divergence. Instead, following Webber's (1969) classic contribution, divergence has taken on a special meaning and refers to the persisting of cross-national differences in cultural value orientations (see, also, Pudelko 2006).

Ultimately, the question whether differences in the cultural values of managers are converging or persisting is, of course, an empirical question. However, as mentioned in the introduction, precisely on this count there is growing concern that the literature is incomplete, lacking credible international generalizations, and has gathered its evidence using imperfect research designs.

\section{Generational Values Shifts and Cohort Replacement as the Mechanism Behind Cultural Change}

Given that countries in general, and managers from different countries in particular, are known to differ in their cultural value orientations (e.g., House et al. 2004; Schwartz 1994), convergence requires value change at the societal level. Though not often recognized in the business and organization literature, this gives the convergence versus divergence debate strong roots in the long-standing literature on cultural change, involving such scholars as Émile Durkheim and Karl Marx, and Marquis de Condorcet before them. Sociologists (as well as, for instance, developmental psychologists) have long understood the mechanism that can bring about societal-level value change even when people's values themselves are relatively stable and do not change much after adolescence (Hitlin 
and Piliavin 2004; Inglehart and Welzel 2005). The mechanism revolves around birth cohorts that have the potential to bring about social change because of the coming of age of a new, younger generation and the retirement of an older generation (Geertz 1963; Mannheim 1928/1929; Ryder 1965). At the societal level, values can change because the values of the younger birth cohort that joins society differ from the values of the older birth cohort that retires. Birth and death drive a mechanism that is known as cohort replacement. However, socialization also plays a critical role. It is through socialization and growing up in different pre-adult social environments that the values of consecutive birth cohorts can exhibit (systematic) shifts toward emphasizing certain values more and other values less.

Realizing the potential for societal-level value change offered by cohort replacement only requires that the values of the older and the younger birth cohorts are different (cf. Twenge et al. 2010) (which, in turn, and as just stated, would be due to different socialization experiences deriving from the societal circumstances that reigned during the pre-adult formative years of a given birth cohort). For actual convergence, mere heterogeneity in socialization experiences or even intergenerational value shifts are not sufficient, however. Since convergence refers to a state in which cultural values of countries are becoming more similar, values need to shift in such a way from one birth cohort to the next that these shifts end up bringing cohorts from different countries and thus countries closer together in terms of their scores on one or more cultural value orientations. Importantly, cultural convergence does not require that all countries move in the same direction with regard to their scores on selected cultural value orientations. Indeed, even if some countries experience a shift toward more emphasis on a particular cultural value while other countries are experiencing a shift toward less emphasis on this particular cultural value, the end result can be a lessening of cross-national differences in this particular cultural value. Figure 1 depicts some stylized scenarios (panels a-c) of intergenerational values shifts that lead to cultural convergence in a sample of seven hypothetical countries. Each scenario is unique, except that in all cases the overall variation in cultural value scores in the sample of hypothetical countries is lower in the younger birth cohort than in the older birth cohort. Meanwhile, cultural divergence, as it has come to be understood in the literature (Webber 1969), implies simply that values are not shifting across older and younger birth cohorts in a way that diminishes initial differences in cultural values between countries.

To be clear, for reasons of space and given the main motivations for this paper, in the analysis of the dynamics of managerial values that follows we do not scrutinize the psychological processes and specific socialization experiences that result in values shifts across birth cohorts and could bring about cultural convergence/divergence. Instead, we jump straight to formulating hypotheses concerning the kind of dynamics of cross-national dissimilarities that we can expect to find in data on the cultural values of managers from different countries and belonging to different birth cohorts.

\section{Hypotheses Development: Convergence, Stability, and/or Divarication}

As just indicated, the hypotheses that we formulate in this subsection are not meant to test novel theoretical arguments but to set the stage for this paper's key goal of presenting large-scale evidence on shifts in the cultural values of managers and the cross-national unification of business cultures. The classic convergence versus divergence literature gives us two basic options for the evolution of cross-national differences in managerial values. Either cross-national differences in the cultural values of managers are waning across birth cohorts, what has been called convergence, or they are remaining, what has been called divergence (Webber 1969). Hypotheses 1a and 1b summarize these two basic options, the theoretical rationale for which has been extensively argued and elaborated on in such prior research as Harbison and Myers (1959), Hofstede (2001) or Ralston (2008):

Hypothesis 1a Cross-national differences in some cultural values of managers are decreasing across older and younger birth cohort so as to exhibit convergence.

Hypothesis 1b Cross-national differences in some cultural values of managers are neither decreasing nor increasing across older and younger birth cohorts so as to exhibit stability.

Importantly, though, and in line with our earlier remark concerning the dictionary meaning of divergence (cf. Pudelko 2006), simply logic suggests the existence, in principle at least, of a third basic option, the actual growing apart of the cultural values of managers. Moreover, it seems sensible to have a basic taxonomy of cultural change that recognizes the theoretical possibility of business cultures becoming more dissimilar. We propose such a taxonomy below, before presenting a theoretical case as to why cultures could in fact be growing apart on certain dimensions of cultural values.

As stated, the convergence/divergence literature has come to settle on its own, non-dictionary definition of the term divergence. For our proposed taxonomy, we simply suggest to unbundle and replace the term divergence with two alternative terms, in addition to cultural convergence. Given the dictionary definition of divergence, we think that 


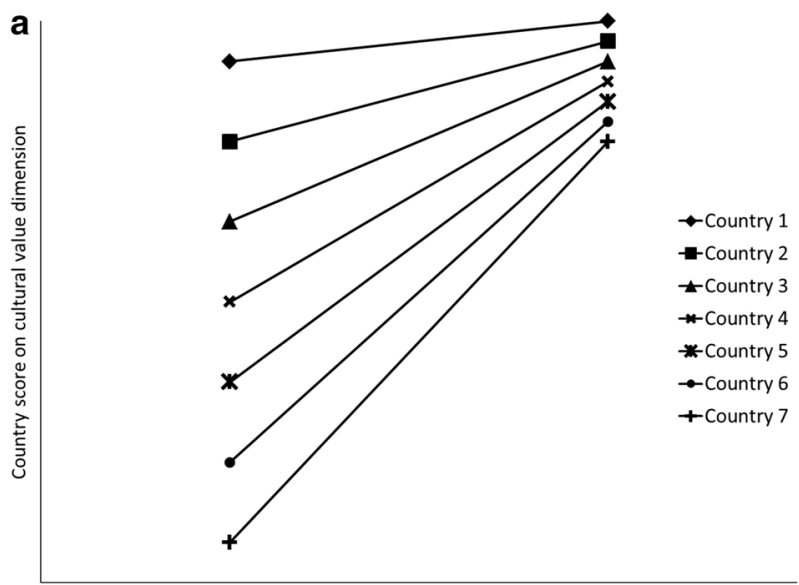

Scores of older birth cohort Scores of younger birth cohort

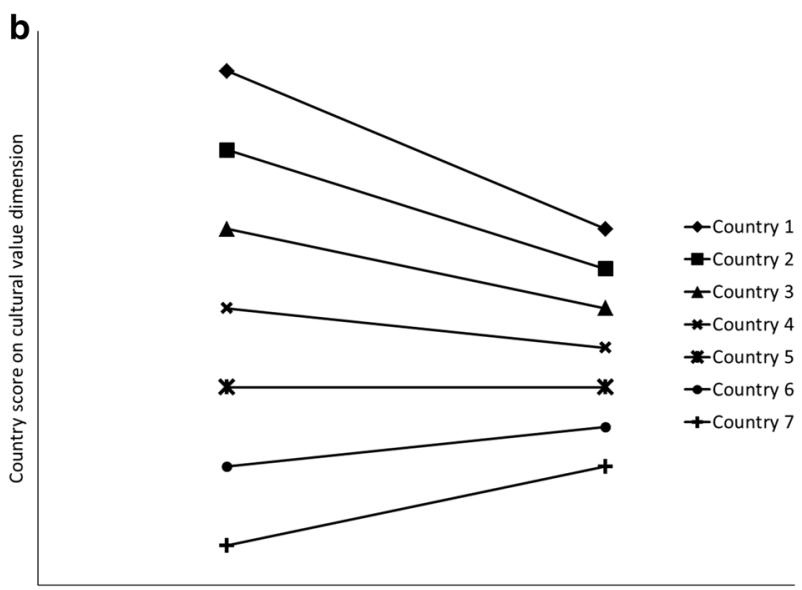

Scores of older birth cohort Scores of younger birth cohort

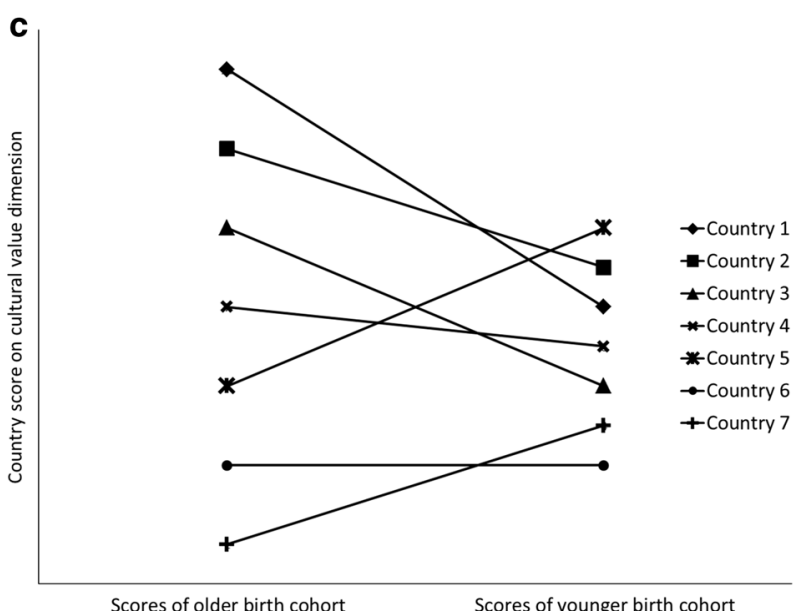

Fig. 1 Stylized scenarios for cultural convergence in a sample of seven hypothetical countries

doing so helps avoid confusion. We label these two alternative terms cultural divarication and cultural stability. Cultural divarication thereby refers to the growing apart of cultures, while cultural stability refers to the situation in which cultures are neither converging nor divaricating, i.e., the persistence of cross-national dissimilarities in cultural values (what has come to be called divergence in the standard convergence/divergence terminology). Akin to Fig. 1 on cultural convergence, Figs. 3 and 4 in Appendix present stylized scenarios of values shifts across birth cohorts that would give rise to cultural stability and cultural divarication, respectively. Meanwhile, although the possibility of hybrid forms of cultural change-convergence in some culture dimensions but persistent cross-national dissimilarities in other culture dimensions - has already been acknowledged (see, for instance, Ralston et al. 1997), actual divarication seems largely neglected.

Although having intuitive appeal, the open question is of course whether we can actually expect to observe cultural divarication in the real world. Perhaps cultural divarication has been neglected for good cause? However, we find reason to believe that cultural divarication may exist. Specifically, insights from evolutionary psychology and theoretical biology suggest that cultural divarication is a distinct possibility. Starting point is the idea that the culture observed in a society reflects but one stable equilibrium out of many possible equilibria (Boyd and Richerson 1985; Maynard Smith 1988; see Cohen 2001 for a synopsis). Hence, although cultures have evolved as adaptations to ecological and environmental circumstances, when different societies face the same conditions they do not necessarily evolve the same cultural response. A straightforward example is the adoption of different norms in society. Norms prescribe a certain type of behavior but exactly which behavior ends up being prescribed can be more or less random, particularly when it is unclear whether one norm is intrinsically "better" than the other norm is. At the same time, though, what is not random is that all people will end up adhering to whichever norm gets adopted. The reason is that adherence to the norm is the only stable equilibrium in this situation. ${ }^{3}$ Accordingly, we have reason to believe that sometimes societies' cultures will grow apart, as even societies with initially similar cultures may take diverging paths in their cultural responses to changing (ecological and environmental) circumstances. Meanwhile, the opposite finding also holds of course. Societies that are highly dissimilar may become slightly more similar because they develop the same cultural responses to a particular change in circumstances. Still, it appears quite possible for cultures to divaricate. Hence, we conclude by proposing the following hypothesis, which combines the idea of multiple stable equilibria mapping onto distinct societal cultures (Cohen 2001) with the convergence-stability-divarication taxonomy that we introduced above:

\footnotetext{
${ }^{3}$ In formal terms, norm adherence is the Nash equilibrium in a coordination game (see, for example, Ullmann-Margalit 1977).
} 
Hypothesis 1c Cross-national differences in some cultural values of managers are increasing across older and younger birth cohorts so as to exhibit divarication.

The next section develops the empirical approach that allows us to test these hypotheses in a large-scale crossnational sample of managers.

\section{Materials and Methods}

\section{Empirical Approach}

Following theories of cultural value change that highlight cohort replacement and generational value shifts as key elements of the mechanism behind cultural convergence/divergence, the empirical approach to studying the dynamics of cross-national differences in the cultural values of managers that we develop in this paper revolves around birth cohorts. The main challenge in designing our research is how to expand the number of countries that we can analyze simultaneously so as to address the problem of international generalizability and present evidence on countries not hitherto considered. Small-scale studies of the type that currently dominate the literature are methodologically straightforward. Typically, the research design involves comparing mean values scores for two countries, looking at the statistical significance of the differences, and then concluding whether values are converging or not. Such a comparison is neither feasible for a large-scale study such as the present one, nor do we want to let our analysis boil down to a simple yes-or-no answer that hides so much of why we are interested in learning about the dynamics of managerial values in the first place.

Our solution to this challenge is to apply the concept of sigma convergence. Sigma convergence refers to decreasing dispersion or variance in the level of a particular variable across countries. ${ }^{4}$ Economists use sigma convergence to examine time trends in cross-country income differences (Quah 1993; Sala-i-Martin 1996). They calculate the standard deviation or variance across the countries in their sample for several years in a row and run a timeseries regression to see whether this standard deviation (and hence dispersion across countries) is decreasing or increasing over time. Our adaptation is that, following

\footnotetext{
${ }^{4}$ The sigma of sigma convergence thus refers to the standard deviation or variance of the sample for the variable of interest. To be sure, the standard deviation or variance that we consider does not relate in any way to intra-country values diversity, which empirical research increasingly shows to be an important source of differences in personal values (Fischer and Schwartz 2011; Van Hoorn 2015b). In fact, as cultural values are societal-level constructs, by definition, they exhibit only inter-country variation and no corresponding variation within countries.
}

theories of cultural value change, we look at consecutive birth cohorts rather than a regular time trend and at the variance in countries' cultural values scores for these birth cohorts. Specifically, we calculate the variance in cultural values scores across all the countries in our sample, separately for each birth cohort in the analysis.

Initially, we keep our empirical analysis as simple as possible, focusing on cultural values dissimilarities across two birth cohorts. The defining of these two birth cohorts is an important free parameter in our analysis. For our baseline analysis, we apply the most straightforward definition that we can think of, which is to use the end of WWII as the defining event/cutoff point. This way, we have an older cohort comprising all managers born before 1945 (average birth year 1935 and average age 71.6 years) and a younger cohort comprising all managers born in 1945 or after (average birth year 1964 and average age 41.5 years). Table 2 presents details on these two birth cohorts for the sample as a whole and for each of the countries in our sample separately. The accompanying empirical test concerns the equality of cross-country variance in cultural values scores for these two birth cohorts. Specifically, we use Levene's test to assess whether crosscountry variance is statistically significantly higher or lower in the younger birth cohort compared to the older birth cohort, separately for each of the seven cultural value orientations. If we find the former, this signifies cultural divarication, while the latter signifies cultural convergence. Absent any statistically significant difference in crosscountry variance in cultural value scores for the two birth cohorts $(p>.1)$, we conclude that cultural differences are stable.

As the choice for the year 1945 as the cutoff point for defining the two birth cohorts in our baseline analysis is essentially arbitrary, as a test of the robustness of these initial results we also consider an alternative definition of birth cohorts. Rather than 1945, we pick the year 1969, known for the Apollo moon landing among various other events. In this case, we define the older cohort as all managers that were born before 1969 and the younger cohort as all managers that were born in 1969 or later.

As a further robustness check, we increase the number of birth cohorts that we identify and use regression analysis akin to studies of cross-country income differences (Quah 1993; Sala-i-Martin 1996). Specifically, we estimate a simple linear trend in the dispersion measure (the dependent variable) using average birth year of a larger number of birth cohorts as the independent variable. In this case, the empirical evidence on cultural convergence, stability, and/or divarication comes in the form of the sign and significance of the estimated coefficient for the average birth year of cohorts, one coefficient for each of the seven cultural value orientations. A significant negative coefficient signifies convergence (a 
decrease in cross-country variance), a significant positive coefficient signifies divarication (an increase in crosscountry variance), and a coefficient that is insignificant signifies cultural stability. Importantly, the number of distinct birth cohorts that we identify determines the number of observations for this regression analysis; one score capturing the variance in cultural values scores among the countries in our sample for each birth cohort. The decision on the number of birth cohorts, in turn, is an important free parameter in this extension to our baseline analysis. For simplicity, we identify 20 birth cohorts, where we choose the years of birth belonging to each of the 20 birth cohorts in such a way that we have roughly the same number of individual observations per birth cohort. Of course, the definition of birth cohorts that we end up with remains essentially arbitrary (see above). At this point, however, we think that choosing a roughly equal amount of individual-level observations in each of the 20 birth cohorts is the least arbitrary choice.

A final important free design parameter in our empirical approach is the minimum number of individual observations per country per birth cohort that we require as a way of ensuring representativeness. For the baseline analysis, we set the minimum number of country-specific individual observations at 20 per birth cohort, which the work of Hofstede (e.g., Hofstede 2001) suggests is adequate. However, because having at least 50 observations would be better still (Hofstede and Minkov 2013), as one of our robustness checks we repeat our baseline analysis using a sample that excludes countries with fewer than 50 observations in either the pre-1945 birth cohort or the later birth cohort. Importantly, though, the number of 20 observations already compares very favorably to the most recent exercise in providing large-scale quantitative evidence on cultural differences between countries, the famous GLOBE project (House et al. 2004), which has used as few as 13 observations per country. ${ }^{5}$ In general, however, it is good to realize that our empirical approach faces a trade-off between the number of birth cohorts that one would like to identify, the minimum number of country-specific individual observations that one requires per birth cohort, and the number of countries that one is able to include in the analysis. Considering additional birth cohorts leaves fewer country-specific individual observations per birth cohort, meaning that some countries would need to be removed

\footnotetext{
5 Specifically, in the GLOBE project, the number of individual observations per country ranged from 27 to 1790 (House et al. 2004). However, the GLOBE project divided respondents in two halves, each of which completed a different questionnaire that pertained to different measures of the culture dimensions identified in the GLOBE culture framework. As a result, the GLOBE culture scores are based on as few as 13 observations per country. On average, the GLOBE culture scores have been based on 251 individual respondents per country (House et al. 2004), while our analysis comprises more than 2000 individuals per country on average.
}

from the analysis because they no longer meet the criterion for the minimum number of observations per birth cohort.

\section{Measures and Sample}

Our data come from the well-known European Social Survey or ESS. We use the accumulated data file that covers the first six biannual waves of the ESS, conducted in 2002, 2004, 2006, 2008, 2010, and 2012 (European Social Survey 2014). This means that we do not just have timeseries data on the cultural values of managers measured at two different points in time but that we have a panel of up to six repeated cross-sections over a period of 11 years. As such, the data allow for an almost ideal research design to study (values) shifts across birth cohorts (Ryder 1965).

As mentioned, the actual value measures derive from the framework of cultural values by Schwartz (e.g., Schwartz 1994, 2006). As alluded to earlier, this framework has key advantages over other frameworks, notably Hofstede (2001), in that it derives the values from ex ante theorizing that identified the comprehensive dimensions needed to describe societies' culture (Berry et al. 2010; Brett and Okumura 1998; Shin and Zhou 2003) (see, also Note 1). The value measures are collected through the Portrait Values Questionnaire or PVQ (Schwartz et al. 2001). The PVQ is highly similar to the Schwartz Values Survey or SVS, which is older and therefore used more often by organization and business ethics scholars researching values. The difference between the SVS and the PVQ is that the design of the PVQ has been improved to make the questionnaire items more understandable for respondents (Schwartz et al. 2001). To elaborate, whereas the SVS is designed to elicit direct self-reports of respondents' values, the PVQ does so indirectly. The essential difference between the SVS and the PVQ therefore is that respondents face a different judgment task. In the SVS, respondents provide a rating of values as guiding principles in their lives and are fully aware of the aim of the survey. In the PVQ, in contrast, respondents are not required to think about and assess their values but merely to describe themselves relative to portraits provided by the survey (Schwartz et al. 2001). Hence, the cognitive process involved is different and the PVQ never explicitly mentions that it is meant to capture people's values. As it is easier to answer, the PVQ does a better job of measuring the values of certain groups, not least the less educated, than the SVS does. The PVQ is widely used across social science disciplines, increasingly also in management research, including business ethics (Graf et al. 2011, 2012; Van Hoorn 2015a, 2015c).

The version of the PVQ included in the ESS consists of 21 questionnaire items that can be used to measure the seven dimensions in the standard cultural values framework by Schwartz. As just indicated, the basic outline of the items is that they ask respondents to describe themselves by 
Table 2 Country samples $(N=32)$

\begin{tabular}{|c|c|c|}
\hline \multirow[t]{2}{*}{ Country } & \multicolumn{2}{|l|}{ Mean age and mean birth year } \\
\hline & $\begin{array}{l}\text { Pre-1945 birth cohort (older } \\
\text { cohort) }\end{array}$ & $\begin{array}{l}\text { Birth cohort } 1945 \text { and after } \\
\text { (younger cohort) }\end{array}$ \\
\hline Austria $(n=1747)$ & 68.5 and $1935(n=458)$ & 41.5 and $1962(n=1289)$ \\
\hline Belgium $(n=3129)$ & 71.8 and $1935(n=691)$ & 42.8 and $1964(n=2438)$ \\
\hline Bulgaria $(n=1249)$ & 72.7 and $1936(n=372)$ & 47.5 and $1962(n=877)$ \\
\hline Croatia $(n=552)$ & 72.2 and $1937(n=128)$ & 44.6 and $1964(n=424)$ \\
\hline Cyprus $(n=929)$ & 72.5 and $1937(n=177)$ & 44.3 and $1965(n=752)$ \\
\hline Czech Republic $(n=1613)$ & 70.3 and $1935(n=447)$ & 45.2 and $1962(n=1166)$ \\
\hline Denmark $(n=2930)$ & 70.9 and $1936(n=710)$ & 43.9 and $1963(n=2220)$ \\
\hline Estonia $(n=2248)$ & 73.6 and $1935(n=566)$ & 42.0 and $1967(n=1682)$ \\
\hline Finland $(n=2576)$ & 71.5 and $1935(n=691)$ & 45.2 and $1962(n=1885)$ \\
\hline France $(n=3486)$ & 71.9 and $1935(n=918)$ & 43.5 and $1964(n=2568)$ \\
\hline Germany $(n=5163)$ & 70.8 and $1936(n=1439)$ & 44.2 and $1963(n=3724)$ \\
\hline Greece $(n=1544)$ & 70.7 and $1934(n=414)$ & 41.8 and $1964(n=1130)$ \\
\hline Hungary $(n=1285)$ & 70.8 and $1935(n=426)$ & 45.1 and $1962(n=859)$ \\
\hline Iceland $(n=542)$ & 71.4 and $1937(n=82)$ & 41.3 and $1967(n=460)$ \\
\hline Ireland $(n=3059)$ & 71.3 and $1936(n=623)$ & 41.2 and $1966(n=2436)$ \\
\hline Israel $(n=2365)$ & 72.9 and $1934(n=456)$ & 41.7 and $1966(n=1909)$ \\
\hline Italy $(n=510)$ & 70.0 and $1936(n=104)$ & 43.8 and $1964(n=406)$ \\
\hline Lithuania $(n=480)$ & 73.8 and $1937(n=95)$ & 44.2 and $1967(n=385)$ \\
\hline Luxembourg $(n=434)$ & 68.0 and $1936(n=101)$ & 40.8 and $1963(n=333)$ \\
\hline Netherlands $(n=4291)$ & 71.5 and $1935(n=1078)$ & 42.8 and $1964(n=3213)$ \\
\hline Norway $(n=3224)$ & 71.5 and $1935(n=665)$ & 42.9 and $1964(n=2559)$ \\
\hline Poland $(n=2091)$ & 71.2 and $1935(n=430)$ & 42.9 and $1964(n=1661)$ \\
\hline Portugal $(n=1798)$ & 72.1 and $1935(n=549)$ & 43.0 and $1964(n=1249)$ \\
\hline Russia $(n=1788)$ & 72.7 and $1936(n=303)$ & 42.6 and $1967(n=1485)$ \\
\hline Slovakia $(n=1664)$ & 71.4 and $1936(n=343)$ & 44.1 and $1964(n=1321)$ \\
\hline Slovenia $(n=2292)$ & 70.6 and $1936(n=520)$ & 42.5 and $1964(n=1772)$ \\
\hline Spain $(n=2244)$ & 71.8 and $1935(n=408)$ & 41.9 and $1966(n=1836)$ \\
\hline Sweden $(n=2749)$ & 72.5 and $1934(n=766)$ & 43.7 and $1964(n=1983)$ \\
\hline Switzerland $(n=3702)$ & 71.5 and $1934(n=974)$ & 42.3 and $1964(n=2728)$ \\
\hline Turkey $(n=224)$ & 68.8 and $1936(n=29)$ & 36.3 and $1970(n=195)$ \\
\hline Ukraine $(n=2091)$ & 71.1 and $1936(n=527)$ & 43.7 and $1964(n=1564)$ \\
\hline UK $(n=4709)$ & 73.5 and $1933(n=1265)$ & 42.5 and $1965(n=3444)$ \\
\hline Whole sample $(n=68,708)$ & 71.6 and $1935(n=16,755)$ & 41.5 and $1964(n=51,953)$ \\
\hline
\end{tabular}

Number of individual managers in parentheses. For one of our robustness checks, we exclude Turkey for having fewer than 50 individual observations in the older birth cohort (pre-1945) (see Table 5). After Turkey, the country with the lowest number of individual observations in any of the two birth cohorts is Iceland with 82 observations in the pre-1945 birth cohort

responding to a "portrait" that describes a particular person. An item thus starts with a description, for example, "It is important to her/him to be loyal to her/his friends. She/he wants to devote herself/himself to people close to her/him," and then asks respondents how much the described person is like them: 1, Very much like me-6, Not like me at all. Schwartz (2006) presents the procedure for using the 21 items of the PVQ to construct country scores on the seven dimensions of his cultural values framework. Table 8 in
Appendix presents the 21 items of the PVQ, while Schwartz (2006) provides detailed background information on the measurement of cultural values using his PVQ.

As an important first step, we ipsatized all individual ratings, meaning that we calculated individuals' average score on the 21 items combined and then subtracted this average score from individuals' scores on each item. The reason is that in the Schwartz cultural values framework, values do not have absolute importance but only importance 
relative to other values. Ipsatization renders standardized values measures with scores indicating how weak or strong this value is relative to the other values. As a second step, we combined the ipsatized scores on the 21 items to construct individual ratings on the seven cultural value orientations. Finally, we can calculate countries' cultural values by aggregating the individual ratings, separately for each birth cohort identified. However, as one of our key advances over extant studies of cultural convergence we seek to control for both age and period effects that would otherwise confound any results on values shifts across birth cohorts (Hofstede 2001; Lyons and Kuron 2014; Twenge et al. 2010). To do so, we ran seven regressions with individuals' ratings on the seven dimensions as the dependent variable and year dummies and individuals' age as the independent variables, saving the residuals. These residuals are free from any influences due to age effects or the period of data collection so that we can simply aggregate them to obtain cultural values scores that are free from confounding age and period effects. We calculated age by combining the year of data collection with the answer on the ESS item asking respondents about their year of birth. For maximum flexibility in controlling for age effects, we included a linear, quadratic, and cubic age term in the regressions that we used to obtain the needed residuals.

Beyond cultural values, we identified the managers in the ESS sample by the questionnaire item asking respondents if and how many people they are supervising. We classify as managers all respondents who indicated to supervise at least one person. Depending on further research design choices (see above), the total sample for the analysis comprises 68,708 managers from 32 countries.

Importantly, both the number of countries and the number of individuals in our analysis compare favorably to existing studies of cross-national differences in managerial values that consider non-time-series data on maximum 1000 or 2000 managers from typically two, maybe three countries (columns 3 and 4 in Table 1). Geographically, most of the countries in our sample are located in Europe. Nevertheless, the countries in our sample are strikingly varied in terms of their cultural backgrounds. They belong to 7 out of the 12 main cultural clusters identified by Hofstede (2001) and 6 out of 10 global clusters identified by the GLOBE project (House et al. 2004). Interestingly, GLOBE's cluster framework recognizes that cultural clusters can be more or less close together, and also on this count, our sample appears strikingly diverse. Among the GLOBE clusters present in the sample, there are two sets of clusters that are diametrically opposed. In addition to these clusters, we further consider countries such as Slovakia, Lithuania, and Ukraine that are absent in these standard cultural clusterings. Similarly, our sample comprises several major economic powers (e.g., Germany and France), some small open economies (e.g.,
Denmark and the Netherlands) as well as important transition economies (e.g., Poland). Finally, in terms of formal institutions, the countries included in our sample represent the five major legal traditions recognized in the literature (common law, French law, German law, socialist law, and Scandinavian law) (La Porta et al. 2008). Hence, even though the countries in our sample are geographically clustered in Europe, the sample is quite culturally diverse. More information on the ESS is available from the survey's Web site, http://www.europeansocialsurvey.org.

\section{Empirical Results}

\section{Baseline Results}

Table 3 presents the results of our baseline analysis. Comparing differences in cross-country variance in an older and a younger birth cohort for each of the seven basic cultural values reveals interesting heterogeneity between the different dimensions of cultural value orientations. The majority of dimensions of cultural values, five out of seven, exhibit stability, meaning that cross-country variance in these cultural values neither increases nor decreases statistically significantly between the older and the younger cohort of managers. This result supports Hypothesis $1 b$, as well as the perspective on cross-national values dissimilarities favored by, for instance, Hofstede (e.g., 2001). However, we also find statistically significant evidence of decreasing dissimilarities in the cultural values of managers concerning Affective Autonomy $(p<.1)$, which supports Hypothesis 1a, and resonates with the classic convergence view offered by such researchers as Harbison and Myers (1959) and Inkeles (1960). Strikingly, there is one dimension, Egalitarianism, in which cross-national differences are neither converging nor stable but actually divaricating in a statistically significant manner $(p<.1)$, which supports Hypothesis 1c.

Overall, it seems that the standard taxonomy of convergence and divergence (or hybrid combinations thereof) is a bit too coarse and cannot quite do justice to the dynamics of changing business cultures as they are actually occurring. Rather, even though divarication is comparatively rare, a complete taxonomy of cultural change would do best to incorporate the possibility that cultural dissimilarities between countries are increasing rather than persistent or decreasing.

\section{Robustness Checks and Extensions}

\section{Definition of Older and Younger Birth Cohorts}

As discussed above, an important feature of our empirical approach is that it involves several free design parameters. 
Table 3 Changes in cross-country variance in managers' cultural values

\begin{tabular}{|c|c|c|c|c|c|c|c|}
\hline & Harmony & Embeddedness & Hierarchy & Mastery & $\begin{array}{l}\text { Affective } \\
\text { autonomy }\end{array}$ & $\begin{array}{l}\text { Intellectual } \\
\text { autonomy }\end{array}$ & Egalitarianism \\
\hline $\begin{array}{l}\text { Cross-country variance in pre-1945 } \\
\text { birth cohort }(N=32 \text { and } n=16,755)\end{array}$ & .034 & .030 & .056 & .039 & .105 & .021 & .012 \\
\hline $\begin{array}{l}\text { Cross-country variance in birth cohort } \\
1945 \text { and after }(N=32 \text { and } \\
n=51,953)\end{array}$ & .019 & .030 & .067 & .032 & .057 & .019 & .035 \\
\hline Difference & $\begin{array}{l}-.015 \\
(p=.230)\end{array}$ & $\begin{array}{l}-.000 \\
(p=.847)\end{array}$ & $\begin{array}{l}.011 \\
(p=.909)\end{array}$ & $\begin{array}{l}-.008 \\
(p=.467)\end{array}$ & $\begin{array}{l}-.048 \\
(p=.046)\end{array}$ & $\begin{array}{l}-.002 \\
(p=.636)\end{array}$ & $\begin{array}{l}.024 \\
(p=.001)\end{array}$ \\
\hline Cultural change & Stability & Stability & Stability & Stability & Convergence & Stability & Divarication \\
\hline
\end{tabular}

$P$ values in parentheses. Underlying sample comprises $16,755+51,953=68,708$ managers from 32 countries

Our first robustness check addresses the essentially arbitrary nature of the definition of the older and the younger birth cohort as used for the baseline analysis. Notwithstanding, identifying alternative birth cohorts using 1969 instead of 1945 as the defining year does not change the results much (Table 4 ). The main difference is that the evidence on cultural divarication is no longer statistically significant at usual levels although only barely so ( $p=.100)$. The general pattern of highly heterogeneous dynamics across the seven basic cultural values remains, however (cf. Table 3).

\section{Increasing the Minimum Number of Individual Observations Per Country Per Birth Cohort}

As our second robustness check, we consider a further free design parameter of the baseline analysis, which is the minimum number of country-specific individual observations per birth cohort that we require before including a particular country in the analysis. We selected a minimum number of 20 observations, and although this number compares quite favorable to other work on cultural differences between countries, this number could leave room for random measurement error to affect the results. If so, we would expect results to change when using a different threshold for the minimum number of individual observations per country per birth cohort. Following Hofstede and Minkov (2013), we select a minimum of 50 observations, which reduces our sample to 68,484 individuals from 31 countries.

Results are largely the same as before (Table 5), meaning that we find evidence for convergence of Affective Autonomy values and evidence for divarication of Egalitarianism values, while the other five basic cultural values (Harmony, Embeddedness, Hierarchy, Mastery and Intellectual Autonomy) exhibit stability (cf. Table 3). Hence, it seems that the baseline results are not biased by inclusion of birth cohorts/countries with relatively few underlying individual observations.

\section{Testing for Sigma Convergence Using Regression Analysis}

As a further robustness check, we move beyond testing for the inequality of variances across two birth cohorts and apply a test more akin to the traditional use of sigma convergence in analyses of time trends in cross-country

Table 4 Robustness check: changes in cross-country variance in managers' cultural values across two alternative birth cohorts

\begin{tabular}{|c|c|c|c|c|c|c|c|}
\hline & Harmony & Embeddedness & Hierarchy & Mastery & $\begin{array}{l}\text { Affective } \\
\text { autonomy }\end{array}$ & $\begin{array}{l}\text { Intellectual } \\
\text { autonomy }\end{array}$ & Egalitarianism \\
\hline $\begin{array}{l}\text { Cross-country variance in pre-1969 } \\
\text { birth cohort }(N=32 \text { and } \\
n=50,863)\end{array}$ & .020 & .033 & .057 & .034 & .076 & .022 & .023 \\
\hline $\begin{array}{l}\text { Cross-country variance in birth cohort } \\
1969 \text { and after }(N=32 \text { and } \\
n=17,845)\end{array}$ & .028 & .021 & .079 & .028 & .044 & .012 & .043 \\
\hline Difference & $\begin{array}{l}.008 \\
(p=.515)\end{array}$ & $\begin{array}{l}-.012 \\
(p=.125)\end{array}$ & $\begin{array}{l}.022 \\
(p=.598)\end{array}$ & $\begin{array}{l}-.006 \\
(p=.602)\end{array}$ & $\begin{array}{l}-.033 \\
(p=.069)\end{array}$ & $\begin{array}{l}-.010 \\
(p=.053)\end{array}$ & $\begin{array}{l}.019 \\
(p=.100)\end{array}$ \\
\hline Cultural change & Stability & Stability & Stability & Stability & Convergence & Convergence & Stability \\
\hline
\end{tabular}

$P$ values in parentheses. Underlying sample comprises $50,863+17,845=68,708$ managers from 32 countries 
Table 5 Robustness check: changes in cross-country variance in managers' cultural values with minimum 50 observations per country per birth cohort

\begin{tabular}{|c|c|c|c|c|c|c|c|}
\hline & Harmony & Embeddedness & Hierarchy & Mastery & $\begin{array}{l}\text { Affective } \\
\text { autonomy }\end{array}$ & $\begin{array}{l}\text { Intellectual } \\
\text { autonomy }\end{array}$ & Egalitarianism \\
\hline $\begin{array}{l}\text { Cross-country variance in pre-1945 } \\
\text { birth cohort }(N=32 \text { and } n=16,726)\end{array}$ & .032 & .030 & .054 & .040 & .107 & .021 & .011 \\
\hline $\begin{array}{l}\text { Cross-country variance in birth cohort } \\
1945 \text { and after }(N=32 \text { and } \\
n=51,758)\end{array}$ & .020 & .028 & .067 & .033 & .056 & .017 & .035 \\
\hline Difference & $\begin{array}{l}.012 \\
(p=.438)\end{array}$ & $\begin{array}{l}.002 \\
(p=.675)\end{array}$ & $\begin{array}{l}.014 \\
(p=.849)\end{array}$ & $\begin{array}{l}-.007 \\
(p=.583)\end{array}$ & $\begin{array}{l}.052 \\
(p=.038)\end{array}$ & $\begin{array}{l}.004 \\
(p=.484)\end{array}$ & $\begin{array}{l}.024 \\
(p=.002)\end{array}$ \\
\hline Cultural change & Stability & Stability & Stability & Stability & Convergence & Stability & Divarication \\
\hline
\end{tabular}

$P$ values in parentheses. Underlying sample comprises $16,726+51,758=68,484$ managers from 31 countries. Excluding Turkey, the remaining countries have minimum 82 individual observations in each birth cohort. See Table 2 for details

income differences (Quah 1993; Sala-i-Martin 1996). As described in detail above, we first define 20 instead of two birth cohorts. Second, we calculate the cross-country variance, specifically the standard deviation, in values scores for each of these 20 birth cohorts, separately for each of the seven basic cultural values. The formal statistical test is to model this cross-country variance in cultural values scores as a function of the average birth year of these 20 birth cohorts using regression analysis.

Table 6 presents the results, which are comparable to the results for the baseline analysis but more pronounced (cf. Table 3). Results still indicate convergence in Affective Autonomy values and divarication in Egalitarianism values, as evidenced by a statistically highly significantly negative coefficient for average birth year and a statistically highly significantly positive coefficient for average birth year, respectively (third row of Table 6). However, we also find statistically significant evidence of convergence for three other basic cultural values, namely Embeddedness, Mastery and Intellectual Autonomy.
Similarly, Hierarchy values now also exhibit divarication. In fact, only one basic cultural value dimension remains that does not exhibit any statistically significant trend in cross-country variance across birth cohorts, indicating that cross-national dissimilarities in this dimension are stable. Overall, the results that we obtain using regression analysis and additional birth cohorts provide further support for our hypotheses.

\section{Weighted Versus Unweighted Data}

As a final robustness check, we consider the issue of the weighting of the ESS data. The ESS data set includes socalled design weights that can be used to make the country samples more nationally representative. In general, surveys have difficulty reaching out to and interviewing certain groups of people, while other groups are surveyed with much less difficulty. As a result, certain groups tend to be relatively underrepresented in surveys, while other groups are relatively overrepresented. As a result, country

Table 6 Robustness check: sigma convergence of managers' cultural values across 20 birth cohorts

\begin{tabular}{|c|c|c|c|c|c|c|c|}
\hline & Harmony & Embeddedness & Hierarchy & Mastery & $\begin{array}{l}\text { Affective } \\
\text { autonomy }\end{array}$ & $\begin{array}{l}\text { Intellectual } \\
\text { autonomy }\end{array}$ & Egalitarianism \\
\hline Intercept & $\begin{array}{l}-.309 \\
(p=.571)\end{array}$ & $\begin{array}{l}2.01 \\
(p=.001)\end{array}$ & $\begin{array}{l}-1.76 \\
(p=.001)\end{array}$ & $\begin{array}{l}2.17 \\
(p=.000)\end{array}$ & $\begin{array}{l}5.41 \\
(p=.000)\end{array}$ & $\begin{array}{l}1.84 \\
(p=.001)\end{array}$ & $\begin{array}{l}-3.16 \\
(p=.000)\end{array}$ \\
\hline $\begin{array}{l}\text { Coefficient for average birth } \\
\text { year of cohort }(/ 1000)\end{array}$ & $\begin{array}{l}.248 \\
(p=.376)\end{array}$ & $\begin{array}{l}-.936 \\
(p=.001)\end{array}$ & $\begin{array}{l}1.03 \\
(p=.000)\end{array}$ & $\begin{array}{l}-1.01 \\
(p=.000)\end{array}$ & $\begin{array}{l}-2.63 \\
(p=.000)\end{array}$ & $\begin{array}{l}-.866 \\
(p=.002)\end{array}$ & $\begin{array}{l}1.69 \\
(p=.000)\end{array}$ \\
\hline $\begin{array}{l}\text { No. of observations (=birth } \\
\text { cohorts) }\end{array}$ & 20 & 20 & 20 & 20 & 20 & 20 & 20 \\
\hline $\mathrm{R}^{2}$ & .044 & .451 & .556 & .786 & .887 & .436 & .726 \\
\hline Cultural change & Stability & Convergence & Divarication & Convergence & Convergence & Convergence & Divarication \\
\hline
\end{tabular}

$P$ values in parentheses. The minimum number of country-specific individual observations per birth cohort is 20 . Excluding countries with less than 20 individual observations in any of the 20 birth cohorts that we identify, leaves an underlying sample of 26 countries and 65,966 individual observations. The linear effect of birth year/birth cohort on cross-country dispersion in cultural values scores is in line with analyses of crosscountry income differences (Quah 1993; Sala-i-Martin 1996). Note, though, that it is also possible to estimate a nonlinear specification to allow for increasing/decreasing rates of cultural convergence or divarication 
averages calculated from available individual-level responses can be imprecise. Population weights address this issue, as they provide a correction for the over- and underrepresentation of certain groups in the survey responses relative to their actual presence in society.

So far, we have not applied correction weights, as we are considering subsamples of managers, meaning that our sample is not representative of national averages anyway. However, to err on the safe side, we have also repeated our baseline analysis for a weighted sample. ${ }^{6}$ In line with our argument concerning the limited relevance of design weights, results using a weighted sample are similar to our baseline results (Table 7). Specifically, we still find evidence for convergence of Affective Autonomy values and divarication of Egalitarianism values, while cross-national dissimilarities in the other five value dimensions (Harmony, Embeddedness, Hierarchy, Mastery, and Intellectual Autonomy) again remain stable. Hence, we conclude that our results are robust and not sensitive to the use of design weights.

\section{Conclusion}

\section{Findings and Implications}

The importance of values in shaping behavior, not least behavior concerning a variety of ethical issues and dilemmas, is widely recognized. Accordingly, ever-increasing economic integration and interconnectedness has spawned a large literature on the cultural values of managers and the cross-national convergence/divergence of these values. However, more than 50 years of research as well as insightful past work notwithstanding, there is growing concern that the evidence that has been amassed on the convergence/divergence of managerial values is based on imperfect research designs and lacks international generalizability. In addition, most studies do not pay much attention to intergenerational value shifts and the role of cohorts and cohort replacement in bringing about cultural change. This paper has sought to advance the analysis of changing business cultures and the dynamics of cross-national differences in the cultural values of managers by addressing these challenges. Following theories of value change, we designed our analysis to revolve around birth cohorts. Moreover, by adopting the concept of sigma convergence from studies of cross-country income

\footnotetext{
6 Of course, we could have weighted by country size, i.e., used population weights, as well. However, as weighting by country size would imply that our results are almost completely driven by the larger countries in the sample (Russia, Turkey, and Germany), at the expense of smaller countries such as Denmark, Estonia, and Slovenia, we shy away from considering population weights altogether.
}

differences we are able to consider a larger and more culturally diverse set of countries than earlier work.

For conceptualizing and operationalizing values, we have relied on the famous framework of cultural values by Shalom Schwartz. Based on ex ante theorizing, this framework identifies seven basic cultural value orientations: Egalitarianism, Hierarchy, Harmony, Mastery, Embeddedness, Intellectual Autonomy, and Affective Autonomy. Adopting insights from evolutionary psychology and biology, among others, we proposed that crossnational differences in these seven dimensions are changing but that, in principle at least, they may change in different ways. Some cultural values may exhibit crossnational convergence, while cross-national dissimilarities in other cultural values may be increasing, exhibiting what we call divarication. Meanwhile, other cross-national values differences still may show no sign of either convergence or divarication, exhibiting what we call cultural stability. The empirical results support the existence of such heterogeneous cultural change and are robust to a variety of alterations to our sample and research design. Overall, we conclude that business cultures are indeed changing, but in such subtle ways that a full-fledged convergence-stability-divarication perspective provides the best basis for thinking about the dynamics of cross-national values dissimilarities. Even though divarication is not the norm, the evidence indicates that cultures can in fact grow apart. Future theorizing can probe into this phenomenon more deeply, while additional empirical work is needed to assess exactly how pervasive cultural divarication is.

The generic takeaway from our findings is that when it comes to people's values and the differences between them, the influence of country could be waning but that this is not a given. This, in turn, has implications for a wide range of issues, including, of course, in business ethics. As stated earlier, values concern desirable end states and guide people's actions, including on such ethical issues as judgment of moral behavior in the workplace (Finegan 1994), fair trade consumption (Doran 2009), the evaluation of questionable consumer practices (Steenhaut and Van Kenhove 2006), and ethical decision making (Fritzsche and Oz 2007). The cultural values of a country therefore are an important feature of the societal context in which organizations operate and pursue their goals (Hofstede 2001; Schwartz 1999). Not taking into account cultural context, may negatively affect an organization's societal legitimacy and thereby threaten its very survival (cf. DiMaggio and Powell 1983; Scott 1995). Focusing more narrowly on the business ethics component of the culture-legitimacy nexus, the values in a society determine whether certain organizational practices as well as products sold are dismissed as unethical, perceived as neutral, or endorsed as positively ethical. Meanwhile, our findings on the dynamics of cross- 
Table 7 Robustness check: changes in cross-country variance in managers' cultural values using weighted data

\begin{tabular}{|c|c|c|c|c|c|c|c|}
\hline & Harmony & Embeddedness & Hierarchy & Mastery & $\begin{array}{l}\text { Affective } \\
\text { autonomy }\end{array}$ & $\begin{array}{l}\text { Intellectual } \\
\text { autonomy }\end{array}$ & Egalitarianism \\
\hline $\begin{array}{l}\text { Cross-country variance in pre-1945 } \\
\text { birth cohort }\end{array}$ & .036 & .029 & .061 & .038 & .100 & .021 & .013 \\
\hline $\begin{array}{l}\text { Cross-country variance in birth } \\
\text { cohort } 1945 \text { and after }\end{array}$ & .020 & .030 & .066 & .031 & .056 & .018 & .035 \\
\hline Difference & $\begin{array}{l}-.016 \\
(p=.324)\end{array}$ & $\begin{array}{l}.001 \\
(p=.862)\end{array}$ & $\begin{array}{l}.005 \\
(p=.857)\end{array}$ & $\begin{array}{l}-.007 \\
(p=.524)\end{array}$ & $\begin{array}{l}-.044 \\
(p=.057)\end{array}$ & $\begin{array}{l}-.002 \\
(p=.594)\end{array}$ & $\begin{array}{l}.022 \\
(p=.003)\end{array}$ \\
\hline Cultural change & Stability & Stability & Stability & Stability & Convergence & Stability & Divarication \\
\hline
\end{tabular}

$P$ values in parentheses. Underlying sample comprises 68,708 managers from 32 countries

national values differences are of course especially relevant in the context of border-crossing business activities. For these type of activities, a key practical challenge has always been that practices that are acceptable in one country are less accepted (or even regarded as unethical) in another country (Zaheer 1995). Main implication of our results subsequently is that this challenge appears likely to persist. Even when countries are converging on some basic cultural value dimensions, differences on other dimensions appear to be remaining (or even increasing). In short, organizations cannot assume that, as time passes, they will automatically be able to have a set of universally applicable management practices or to have standardized products that will do equally well in every market worldwide. Instead, what seems required is continuous monitoring of the cultural context in which the organization is operating and constant tailoring of one's way of doing business to the demands set by the different values of societies around the globe.

\section{Limitations and Future Research}

While this paper is meant to address some important challenges raised against extant quantitative convergence/divergence studies, there are several limitations to our research. First, due to the scale of our analysis, we have studied value differences across birth cohorts instead of across clearly defined generation cohorts. Shared pre-adult socialization experiences are at the basis of intergenerational value shifts. Hence, it would have been ideal had we been able to group individuals into cohorts that are clearly delineated on the basis of societal circumstances during childhood. However, such a delineation is not feasible when one seeks to analyze a sample of countries as large and diverse as the sample that we considered. It would require detailed ethnographic evidence as well as the means to make socialization experiences somehow comparable across countries, neither of which seems feasible. Rather, one simply has to make due. Nevertheless, we consider it an interesting next step to actually test the effect of variation in certain generic features of individuals' preadult environment, notably level of economic development, on the values of managers from various countryspecific birth cohorts.

Related to this first limitation, we find that future research may usefully extend the present analysis by letting go of national boundaries. Groups such as birth cohorts that share similar pre-adult experiences and life-history events need not be confined to any single country. Indeed, formative experiences shaping one's values can and do occur at different levels, either transcending country borders or being more localized, applying for instance to groups living in a certain sub-national region. Understanding of values and the dynamics therein may gain a great deal from further consideration of group differences in values with group membership defined on the basis of a range of individual characteristics other than nationality.

This second limitation, in turn, feeds into a third limitation, which is that our focus on cultural values and crossnational dissimilarities neglects the large amount of variation in personal values that occurs within countries. Although we cannot think of any practical method for doing so, it would be interesting if future research could incorporate intra-country diversity in an analysis of crossnational value dissimilarities and convergence/stability/divarication of countries' business cultures. A particularly important open question is how changing within-country diversity might affect between-country value differences.

A fourth limitation is that our focus on cultural convergence, cultural stability, or cultural divarication in a large cross-country sample hides possibly interesting country-specific changes in the cultural values of managers. For instance, while a given cultural value may be divaricating when considering all countries simultaneously, this value might actually be converging when considering specific subsets of countries. On the other hand, the fact that this paper is able to consider a large sample of countries in and of itself is not a weakness but a way for us to present large-scale evidence, which has been unfortunately lacking in the literature. Meanwhile, there is nothing that 
precludes the application of our basic empirical approach and the concept of sigma convergence to smaller crosscountry samples that match extant studies.

Finally, our analysis is no exception to the idea that cultural value change can be studied more accurately the longer the time series of the values data available for empirical analysis. Using data collected during a period of up to 11 years and six different points in time has enabled us to have a research design that can distinguish between genuine birth cohort effects as a key element of the mechanism bringing about societal-level value change and potential confounders. Nevertheless, we can improve on the present study by analyzing a time series that includes even more data points and a longer time period than covered by the data available to us.

Still, though, we think that the possibility of designing research in the way that we have done for this study means that there is much potential for business and organization research to make progress in understanding cross-national value differences and the (intergenerational) dynamics therein. The research design developed for the present study thereby might provide a blueprint for future analyses of changing business cultures. Overall, this paper contributes to establishing an improved evidentiary foundation from which to debate the dynamics of managerial values and the idea of a unified business culture, and also may we now be more wary of how incomplete and limited our knowledge of value change and cultural convergence/divergence still is.

Open Access This article is distributed under the terms of the Creative Commons Attribution 4.0 International License (http://creative commons.org/licenses/by/4.0/), which permits unrestricted use, distribution, and reproduction in any medium, provided you give appropriate credit to the original author(s) and the source, provide a link to the Creative Commons license, and indicate if changes were made.

\section{Appendix}

See Table 8 and Figs. 2, 3 and 4.

Table 8 PVQ value items

Short description $\quad$ Survey item text (portrait)

Important to think new ideas and being creative

Important to be rich, have money and expensive things

Important that people are treated equally and have equal opportunities

Important to show abilities and be admired

Important to live in secure and safe surroundings

Important to try new and different things in life

Important to do what is told and follow rules

Important to understand different people

Important to be humble and modest, not draw attention

Important to have a good time

Important to make own decisions and be free

Important to help people and care for others well-being

Important to be successful and that people recognize achievements

Important that government is strong and ensures safety

Important to seek adventures and have an exciting life

Important to behave properly
Thinking up new ideas and being creative is important to her/him. She/he likes to do things in her/his own original way

It is important to her/him to be rich. She/he wants to have a lot of money and expensive things

She/he thinks it is important that every person in the world should be treated equally. She/he believes everyone should have equal opportunities in life

It is important to her/him to show her/his abilities. She/he wants people to admire what she/he does

It is important to her/him to live in secure surroundings. She/he avoids anything that might endanger her/his safety

She/he likes surprises and is always looking for new things to do. She/he thinks it is important to do lots of different things in life

She/he believes that people should do what they're told. She/he thinks people should follow rules at all times, even when no-one is watching

It is important to her/him to listen to people who are different from her/him. Even when she/he disagrees with them, she/he still wants to understand them

It is important to her/him to be humble and modest. She/he tries not to draw attention to herself/ himself

Having a good time is important to her/him. She/he likes to "spoil" herself/himself

It is important to her/him to make her/his own decisions about what she/he does. She/he likes to be free and not depend on others

It is very important to her/him to help the people around her/him. She/he wants to care for their well-being

Being very successful is important to her/him. She/he hopes people will recognize her/his achievements

It is important to her/him that the government ensures her/his safety against all threats. She/he wants the state to be strong so it can defend its citizens

She/he looks for adventures and likes to take risks. She/he wants to have an exciting life

It is important to her/him always to behave properly. She/he wants to avoid doing anything people would say is wrong 
Table 8 continued

Short description

Important to get respect from others

Important to be loyal to friends and devote to people close

Important to care for nature and environment

Important to follow traditions and customs

Important to seek fun and things that give pleasure
Survey item text (portrait)

It is important to her/him to get respect from others. She/he wants people to do what she/he says

It is important to her/him to be loyal to her/his friends. She/he wants to devote herself/himself to people close to her/him

She/he strongly believes that people should care for nature. Looking after the environment is important to her/him

Tradition is important to her/him. She/he tries to follow the customs handed down by her/his religion or her/his family

She/he seeks every chance she/he can to have fun. It is important to her/him to do things that give her/him pleasure

The generic text accompanying this 21-item battery is: "Now I will briefly describe some people. Please listen to each description and tell me how much each person is or is not like you." As stated in the main text, answers to the items can be given on a Likert-type scale: 1 very much like me; 2 like me; 3 somewhat like me; 4 a little like me; 5 not like me; 6 not like me at all

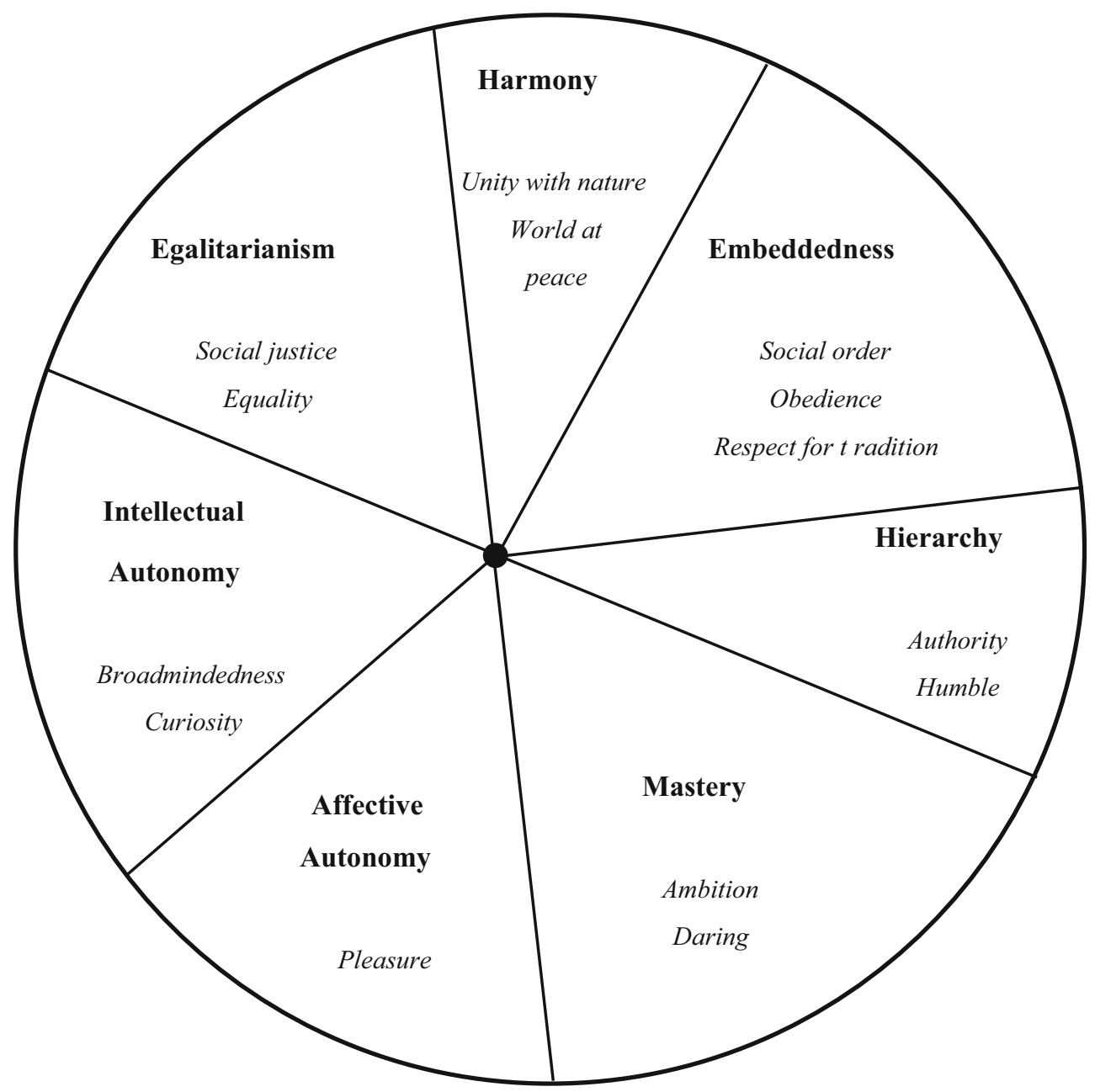

Fig. 2 Seven dimensions of cultural values and their structural interrelatedness. Source is Schwartz (2006, p. 142). Cultural values that are incompatible are opposite to each other. Cultural values that are compatible are adjacent 


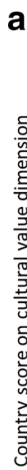

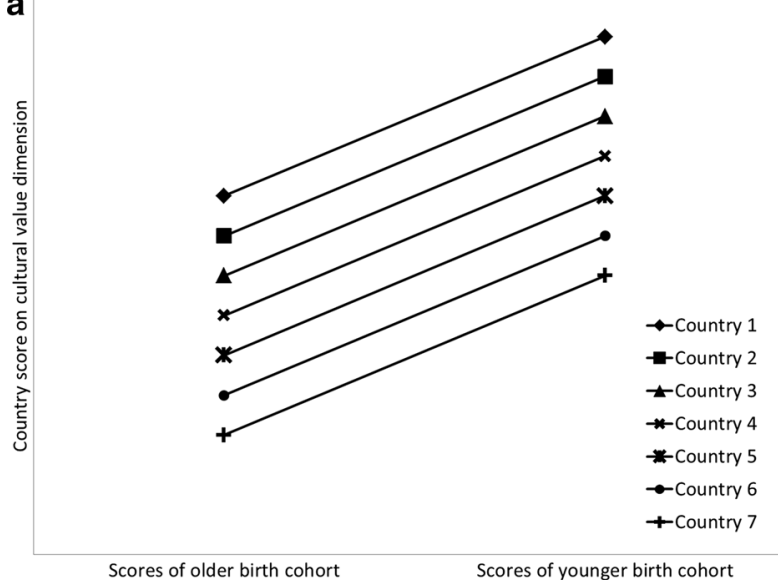

b

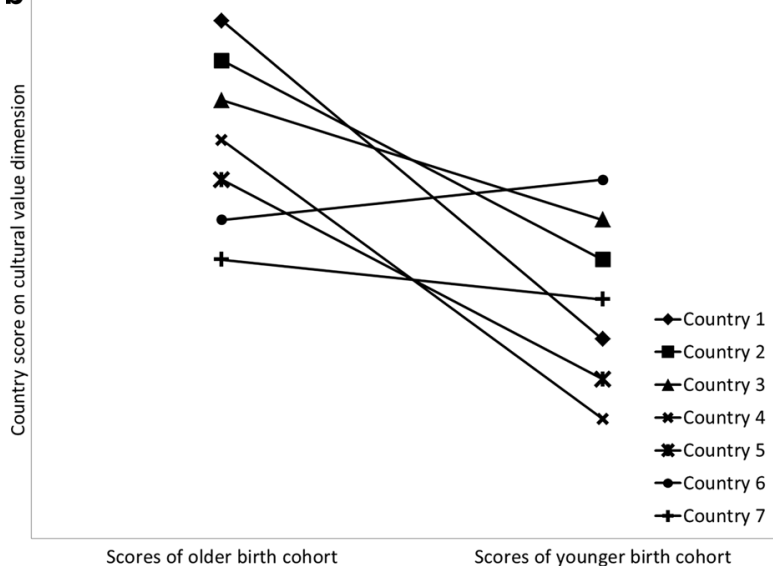

C

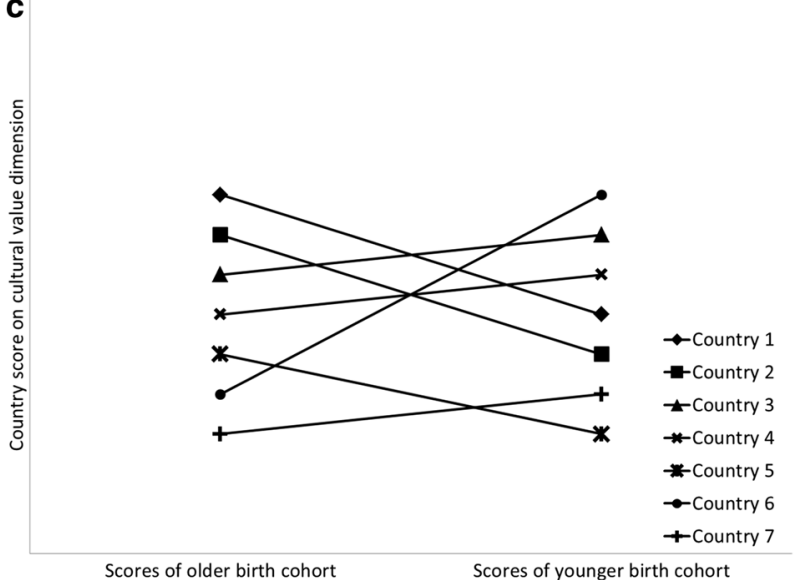

Fig. 3 Stylized scenarios for cultural stability in a sample of seven hypothetical countries
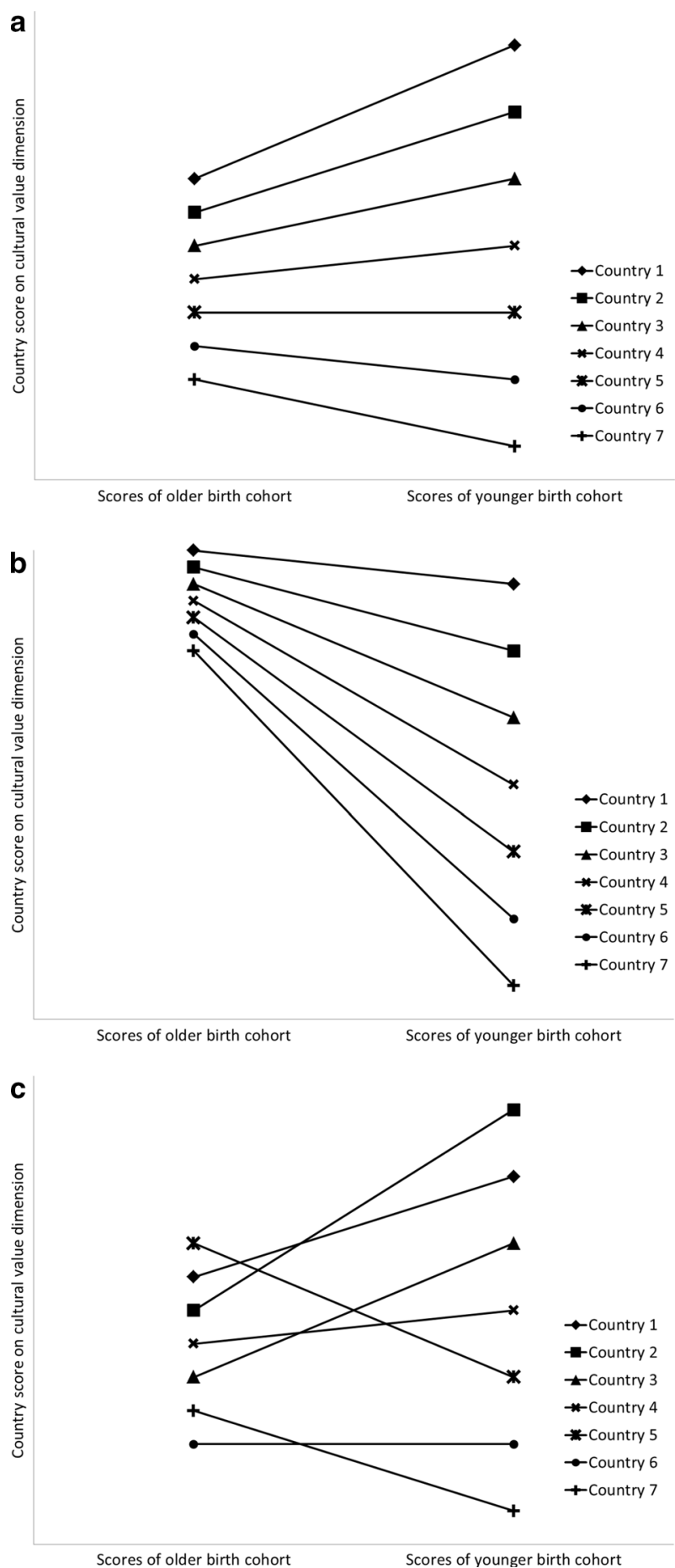

Fig. 4 Stylized scenarios for cultural divarication in a sample of seven hypothetical countries 


\section{References}

Berry, H., Guillén, M., \& Zhou, N. (2010). An institutional approach to cross-national distance. Journal of International Business Studies, 41, 1460-1480.

Beugelsdijk, S., Maseland, R., \& Van Hoorn, A. (2015). Are scores on Hofstede's dimensions of national culture stable over time? A cohort analysis. Global Strategy Journal, 5, 223-240.

Boyd, R., \& Richerson, P. (1985). Culture and the evolutionary process. Chicago: University of Chicago Press.

Brett, J. M., \& Okumura, T. (1998). Inter- and intracultural negotiation: U.S. and Japanese negotiators. Academy of Management Journal, 41, 495-510.

Cohen, D. (2001). Cultural variation: Considerations and implications. Psychological Bulletin, 127, 451-471.

Desai, S. D., Chugh, D., \& Brief, A. P. (2014). The implications of marriage structure for men's workplace attitudes, beliefs, and behaviors toward women. Administrative Science Quarterly, 59, 330-365.

DiMaggio, P. J., \& Powell, W. W. (1983). The iron cage revisited: Institutional isomorphism and collective rationality in organizational fields. American Sociological Review, 48, 147-160.

Doran, C. J. (2009). The role of personal values in fair trade consumption. Journal of Business Ethics, 84, 549-563.

Dunphy, D. (1987). Convergence/divergence: A temporal review of the Japanese enterprise and its management. Academy of Management Review, 12, 445-459.

Egri, C. P., \& Ralston, D. A. (2004). Generation cohorts and personal values: A comparison of China and the U.S. Organization Science, 15, 210-220.

England, G. W. (1967). Personal value systems of American managers. Academy of Management Journal, 10, 53-68.

European Social Survey. (2014). Cumulative file, ESS 1-6. Data file edition 1.1. Norwegian Social Science Data Services, NorwayData archive and distributor of ESS data.

Finegan, J. (1994). The impact of personal values on judgments of ethical behaviour in the workplace. Journal of Business Ethics, 13, 747-755.

Fischer, R., \& Schwartz, S. (2011). Whence differences in value priorities?: Individual, cultural, or artifactual sources. Journal of Cross-Cultural Psychology, 42, 1127-1144.

Franke, G. R., \& Richey, R. G., Jr. (2010). Improving generalizations from multi-country comparisons in international business research. Journal of International Business Studies, 41, $1275-1293$.

Fritzsche, D. J. (1995). Personal values: Potential keys to ethical decision making. Journal of Business Ethics, 14, 909-922.

Fritzsche, D., \& Oz, E. (2007). Personal values' influence on the ethical dimension of decision making. Journal of Business Ethics, 75, 335-343.

Geertz, C. (1963). Peddlers and princes: Social change and economic modernization in two Indonesian towns. Chicago: University of Chicago Press.

Graf, M. M., Schuh, S. C., Van Quaquebeke, N., \& van Dick, R. (2012). The relationship between leaders' group-oriented values and follower identification with and endorsement of leaders: The moderating role of leaders' group membership. Journal of Business Ethics, 106, 301-311.

Graf, M. M., Van Quaquebeke, N., \& Van Dick, R. (2011). Two independent value orientations: Ideal and counter-ideal leader values and their impact on followers' respect for and identification with their leaders. Journal of Business Ethics, 104, 185-195.

Hamamura, T. (2012). Are cultures becoming individualistic? A cross-temporal comparison of individualism-collectivism in the
U.S. and Japan. Personality and Social Psychology Review, 16, 3-24.

Harbison, F., \& Myers, C. (1959). Management in the industrial world-An international analysis. New York: McGraw-Hill.

Heuer, M., Cummings, J. L., \& Hutabarat, W. (1999). Cultural stability or change among managers in Indonesia? Journal of International Business Studies, 30, 599-610.

Hitlin, S., \& Piliavin, J. A. (2004). Values: Reviving a dormant concept. Annual Review of Sociology, 30, 359-393.

Hofstede, G. (2001). Culture's consequences: Comparing values, behaviors, institutions, and organizations across nations (2nd ed.). Thousand Oaks: Sage.

Hofstede, G., Hofstede, G.-J., \& Minkov, M. (2010). Cultures and organizations: Software of the mind (3rd ed.). New York: McGraw-Hill.

Hofstede, G., \& Minkov, M. (2013). Values survey module 2013 manual. August 25, 2013, retrieved from www.geerthofstede.nl.

House, R. J., Hanges, P. J., Javidan, M., Dorfman, P., \& Gupta, V. (2004). Culture, leadership, and organizations: The GLOBE study of 62 societies. Thousand Oaks: Sage.

Inglehart, R., \& Welzel, C. (2005). Modernization, cultural change and democracy: The human development sequence. New York: Cambridge University Press.

Inkeles, A. (1960). Industrial man: The relation of status to experience, perception, and values. American Journal of Sociology, 66, 1-31.

Joshi, A., Dencker, J. C., \& Franz, G. (2011). Generations in organizations. Research in Organizational Behavior, 31, 177-205.

Joshi, A., Dencker, J. C., Franz, G., \& Martocchio, J. J. (2010). Unpacking generational identities in organizations. Academy of Management Review, 35, 392-414.

Kelly, L., \& Reeser, C. (1973). the persistence of culture as a determinant of differentiated attitudes on the part of American managers of Japanese ancestry. Academy of Management Journal, 16, 67-76.

La Porta, R., Lopez-de-Silanes, F., \& Shleifer, A. (2008). The economic consequences of legal origins. Journal of Economic Literature, 46, 285-332.

Leung, K., Bhagat, R. S., Buchan, N. R., Erez, M., \& Gibson, C. B. (2005). Culture and international business: Recent advances and their implications for future research. Journal of International Business Studies, 36, 357-378.

Lyons, S., \& Kuron, L. (2014). Generational differences in the workplace: A review of the evidence and directions for future research. Journal of Organizational Behavior, 35, S139-S157.

Mannheim, K. (1928/1929 [1952]). The problem of generations. Reprinted In Kecskemeti, P. (Ed.), Essays on the sociology of knowledge (pp. 276-322). London: Routledge \& Kegan Paul.

Maseland, R., \& Van Hoorn, A. (2017). Culture at the country level. In H. Van Herk, \& C. J. Torelli (Eds.), Cross-cultural issues in consumer science and international business. Berlin: Springer (in press).

Maynard Smith, J. (1988). Did Darwin get it right? Essays on games, sex, and evolution. New York: Chapman \& Hall.

Meglino, B. M., \& Ravlin, E. C. (1998). Individual values in organizations: Concepts, controversies, and research. Journal of Management, 24, 351-389.

Murphy, E. F., Woodhull, M. D., Post, B., Murphy-Post, C., Teeple, W., \& Anderson, K. A. (2006). 9/11 impact on teenage values. Journal of Business Ethics, 69, 399-421.

Pekerti, A. A., \& Arli, D. (2015). Do cultural and generational cohorts matter to ideologies and consumer ethics? A comparative study of Australians, Indonesians, and Indonesian Migrants in Australia. Journal of Business Ethics. doi:10.1007/s10551-0152777-z. 
Pudelko, M. (2006). Universalism, particularism and singularism in cross-national management. International Studies of Management \& Organization, 36, 9-38.

Quah, D. (1993). Galton's fallacy and tests of the convergence hypothesis. Scandinavian Journal of Economics, 95, 427-443.

Ralston, D. A. (2008). The crossvergence perspective: Reflections and projections. Journal of International Business Studies, 39, $27-40$.

Ralston, D. A., Holt, D. H., Terpstra, R. H., \& Kai-Cheng, Y. (1997). The impact of national culture and economic ideology on managerial work values: A study of the United States, Russia, Japan, and China. Journal of International Business Studies, 28, 177-207.

Ralston, D. A., Pounder, J., Lo, C. W. H., Wong, Y. Y., Egri, C. P., \& Stauffer, J. (2006). Stability and change in managerial work values: A longitudinal study of China, Hong Kong and the US. Management and Organization Review, 2, 67-94.

Ricks, D. A., Toyne, B., \& Martinez, Z. (1990). Recent developments in international management research. Journal of Management, 6, 219-253.

Rohan, M. J. (2000). A Rose by any name? The values construct. Personality and Social Psychology Review, 4, 255-277.

Rokeach, M. (1973). The nature of human values. New York: Free Press.

Ryder, N. B. (1965). The cohort as a concept in the study of social change. American Sociological Review, 30, 843-861.

Sala-i-Martin, X. X. (1996). The classical approach to convergence analysis. Economic Journal, 106, 1019-1036.

Schwartz, S. H. (1992). Universals in the content and structure of values: Theory and empirical tests in 20 countries. In M. Zanna (Ed.), Advances in experimental social psychology (Vol. 25, pp. 1-65). New York: Academic Press.

Schwartz, S. H. (1994). Beyond individualism/collectivism: New cultural dimensions of values. In U. Kim, H. C. Triandis, C. Kagitcibasi, S.-C. Choi, \& G. Yoon (Eds.), Individualism and collectivism: Theory, method and applications (pp. 85-119). Newbury Park: Sage.

Schwartz, S. H. (1999). Cultural value differences: Some implications for work. Applied Psychology: An International Review, 48, $23-47$.

Schwartz, S. H. (2006). A theory of cultural value orientations: Explication and applications. Comparative Sociology, 5, 137-182.

Schwartz, S. H., \& Bilsky, W. (1987). Toward a universal psychological structure of human values. Journal of Personality and Social Psychology, 53, 550-562.

Schwartz, S. H., \& Bilsky, W. (1990). Toward a theory of the universal content and structure of values: Extensions and crosscultural replications. Journal of Personality and Social Psychology, 58, 878-891.
Schwartz, S. H., Melech, G., Lehmann, A., Burgess, S., \& Harris, M. (2001). Extending the cross-cultural validity of the theory of basic human values with a different method of measurement. Journal of Cross-Cultural Psychology, 32, 519-542.

Scott, W. R. (1995). Institutions and organizations. Thousand Oaks: Sage.

Shin, S., \& Zhou, J. (2003). Transformational leadership, conservation, and creativity: Evidence from Korea. Academy of Management Journal, 46, 703-714.

Steenhaut, S., \& Van Kenhove, P. (2006). An empirical investigation of the relationships among a consumer's personal values, ethical ideology and ethical beliefs. Journal of Business Ethics, 64, 137-155.

Steenkamp, J. B. E. M. (2001). The role of national culture in international marketing research. International Marketing Review, 18, 30-44.

Twenge, J. M., Campbell, S. M., Hoffman, B. R., \& Lance, C. E. (2010). Generational differences in work values: Leisure and extrinsic values increasing, social and intrinsic values decreasing. Journal of Management, 36, 1117-1142.

Ullmann-Margalit, E. (1977). The emergence of norms. Oxford: Clarendon Press.

Van Hoorn, A. (2015a). The global financial crisis and the values of professionals in finance: An empirical analysis. Journal of Business Ethics, 130, 253-269.

Van Hoorn, A. (2015b). Differences in work values: Understanding the role of intra- versus inter-country variation. International Journal of Human Resource Management, 26, 1002-1020.

Van Hoorn, A. (2015c). Organizational culture in the financial sector: Evidence from a cross-industry analysis of employee personal values and career success. Journal of Business Ethics. doi:10. 1007/s10551-015-2932-6.

Vertinsky, L., Tse, D. K., Wehrung, D. A., \& Lee, K.-H. (1990). Organizational design and management norms: A comparative study of managers' perceptions in the People's Republic of China, Hong Kong, and Canada. Journal of Management, 16, 853-867.

Webber, R. A. (1969). Convergence or divergence? Columbia Journal of World Business, 4, 75-84.

Weber, J. (2015a). Identifying and assessing managerial value orientations: A Cross-generational replication study of key organizational decision-makers' values. Journal of Business Ethics, 132, 493-504.

Weber, J. (2015b). Discovering the Millennials' personal values orientation: A comparison to two managerial populations. Journal of Business Ethics. doi:10.1007/s10551-015-2803-1.

Witt, M. A. (2008). Crossvergence 10 years on: Impact and further potential. Journal of International Business Studies, 39, 47-52.

Zaheer, S. (1995). Overcoming the liability of foreignness. Academy of Management Journal, 38, 341-363. 